\title{
Using Serious Games to Train Children and Elicit Fire Safety Behaviour
}

\author{
João E. Almeida ${ }^{1}$, Rosaldo J.F. Rossetti ${ }^{1,2}$, Brígida Mónica Faria ${ }^{3}$, \\ and António Leça Coelho ${ }^{4}$ \\ ${ }^{1}$ Laboratório de Inteligência Artificial e Ciência de Computadores (LIACC), Porto, Portugal \\ ${ }^{2}$ Departamento de Engenharia Informática (DEI) \\ Faculdade de Engenharia da Universidade do Porto (FEUP) \\ Rua Dr. Roberto Frias s/n, 4200-465 Porto, Portugal \\ ${ }^{3}$ Polytechnic Institute of Porto (ESTSP-IPP), Porto, Portugal \\ ${ }^{4}$ Laboratório Nacional de Engenharia Civil (LNEC), Porto, Portugal \\ \{joao.emilio.almeida, rossetti\}@fe.up.pt, \\ btf@estsp.ipp.pt, alcoelho@lnec.pt
}

\begin{abstract}
Serious Games are being increasingly used as a tool for various applications, contrary to the traditional entertainment purpose. One of their application domains is fire safety. Possible injuries from fires are a dangerous safety concern for children, for instance. Another important issue is the elicitation of behavioural knowledge to design and feed simulation models. The lack of human behaviour data is often referred to as a drawback to evacuation simulation designers. This paper addresses the aforementioned matters in respect to: i) acquiring valuable knowledge on children behaviour when facing the urgent need for evacuation; and ii) devising an educational tool. A group of 19 children from an elementary school played two different role plays using a Serious Game and the data of their behaviours was collected. Results were analysed and are here presented. Future work is two-fold: to expand and to refine data collection to other groups such as elderly; to use this data for crowd synthesis particularly for evacuation simulators.
\end{abstract}

Keywords: serious games, fire safety, evacuation, children, behaviour analysis.

\section{Introduction}

The advent of video games has fostered the implementation of Serious Games (SG) with various goals other than entertainment [1]. Fire safety is one in the midst of the various domains of application of SG [2]. Children are amid one of the more vulnerable groups, when facing a fire. While lectures and classroom learning techniques are a possible way to teach fire safety to children, SG-based video games allow them to better retain escape procedures [3].

The use of Virtual Reality (VR) based applications for both simulating situations that are too dangerous for exposing real people and as an aid for training and education is not new $[4,5]$. SG are a good trade-off between the development of 
low-cost and rapid prototyping of VR applications [6]. Unity3D is a successful platform used worldwide for the development of video games presenting high quality graphics, animation and VR features [7]. Our team has used it to develop SG aiming to train occupants for the evacuation procedures out of a building facing the presence of fire or other hazardous situations, for some time and having some experiments so far with good results [8-12]. For this purpose, we have envisaged a framework coined Simulation of Pedestrians and Elicitation of their Emergent Dynamics (SPEED) for the elicitation of human behaviour in emergency situations. This framework consists of a methodological approach aiming at the elicitation of human behaviour in hazardous situations, and at the use of the collected data to breed and grow an artificial society [13].

The experiment described in this paper aims to elicit children behaviour when facing the urgent need of evacuation from a building, also envisaging to educate and train them in such situations.

The remainder of this paper is organised as follows. Section 2 presents some background and related work in the field of SG, behaviour elicitation and fire safety evacuation techniques. Section 3 is used to introduce the experimental setup, whereas in Section 4, the experimental results and tasks to accomplish such realization are detailed. Finally some conclusions are drawn, as well as are future work and developments presented in Section 5.

\section{Background and Related Work}

Before moving further on the explanation of the experimental setup and the results obtained, it is important to introduce some valuable concepts and subjects that underlie this project.

\section{The Serious Games Concept}

Serious Games have gained a great prominence in the Digital Games field within the last years, by using high-definition graphics and state-of-the-art appealing animation software. It presents a great potential as a tool to be used for purposes other than mere entertainment. Their applications span a wide range of domains, naturally including social simulation, where data collection of players' attitudes can be later used for statistical analysis and behavioural pattern recognition [14].

Contrary to the primary purpose of entertainment in traditional digital games, SG are designed with a more serious purpose with respect to the outcomes reflected in changes to the player behaviour [15].

A game is an artificially constructed, competitive activity with a specific goal, a set of rules and constraints that is located in a specific context. SG refer to video games whose application is focused on supporting activities such as education, training, health, advertising, or social change. Freitas [16] has identified a set of benefits from combining SG with other training activities: i) the learners' motivation is elevated; ii) completion rates are higher; iii) possibility of accepting new learners; iv) possibility of creating collaborative activities; v) learn through doing and acquiring experience. 
Other aspects that draw video game players' attention are fantasy elements, challenging situations and the ability to keep them curious about the outcomes of their possible actions [17].

\section{Using Unity3D to Implement Serious Games}

The SG used as example in this research is based on the Unity3D game engine. Unity3D was selected due to its main characteristics: i) powerful graphical interface that allows visual object placement and property changing in runtime (especially useful to rapidly create new scenarios from existing models and assets and quick tweaking of script variables); ii) the ability to develop code in JavaScript, C\# or Boo; iii) simple project deployment for multiple platforms without additional configuration, including for instance the Web which makes it possible to run the game on a Web browser, making it particularly interesting for massive data collection. This last feature is something that we aim to explore in a near future.

\section{Capturing Player's Decisions throughout the Game}

When developing video games for the purpose of entertainment (or a more serious one, such as using the SG concept), a storyboard should be devised with the timeline, sketch up of the story, development and aim [18].

For the goal of collecting data associated with fire safety and building evacuation for later analysis, we put up a set of scenarios with the assistance of an expert panel, using the a methodology called "Delphi process" that is used for the elicitation of knowledge from experts of a certain field [19]. Amidst these scenarios there are three that were used in the experimental setup described in this paper: the alarm identification, the exit-choice dilemma (with five variants) and auditorium (or cinema) with four variants.

\section{Fire Safety and Building Evacuation}

Fire drills are mandatory in many countries [20]. They are performed to test emergency plans but also to educate building's occupants in fire escape procedures. Teaching fire safety skills to children is an important issue to diminish the number of casualties and increase the level of safety culture [21, 22].

This subject is of great importance and has received attention of the scientific community. Virtual Reality CAVE for training children was proposed in [2]. A multiagent evacuation simulation tool using different agent types was developed and reported in [23]. Other examples of research in this field include [2-5]. 


\section{Experimental Setup}

A group of 19 children aged between 6 and 9 years from an elementary school was invited to participate in this experiment, during their holidays. The teacher gave permission and their parents were consulted to give consent for participation.

The experiment lasted for a full day, from 9.00 am until $6.00 \mathrm{pm}$. Each pupil needed between 20 to 30 minutes to complete all game scenarios. After explaining the game and giving the possibility of using the keyboard plus the mouse or the joystick, they had the possibility of playing for a little while to get used to moving the character throughout the virtual environment.

\section{The Exit-Choice Scenario and Its Five Variants}

The first scenario consists of an office room leading to a corridor with two possible exits. Both exit options (left or right) have the same length towards an exit door and are completely symmetrical (see Fig. 1a). The player is placed in a hypothetical fire situation, having to evacuate the building as quickly as possible. The choice is to go left or to go right when leaving the room.
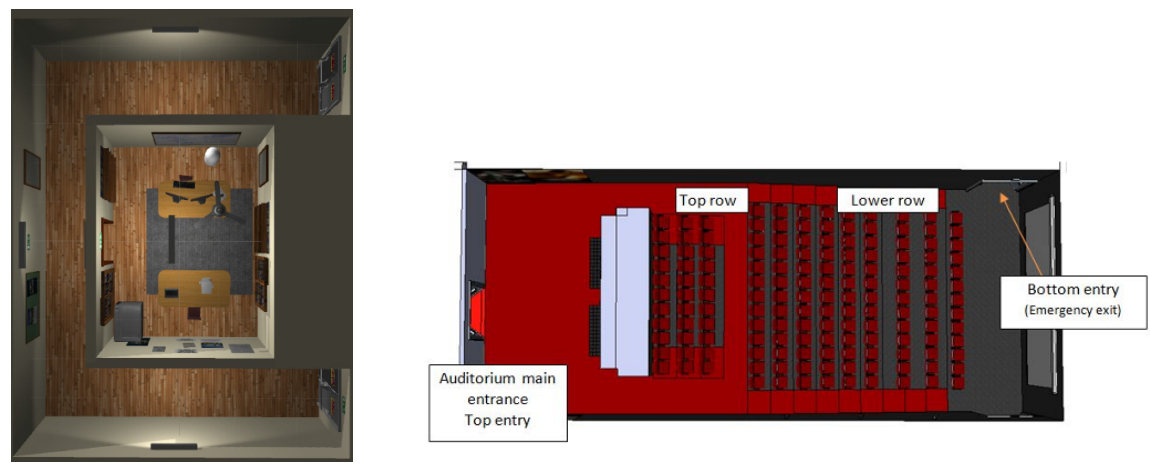

Fig. 1. Game example: a) exit-choice scenario bird view; b) auditorium scenario

There are five variants or scenes which take place in the same scenario. All have the same basis with slight differences: 1) basic scenario, no cues or obstacles; 2) an exit sign pointing to one of the possible exits (left) is added; 3) smoke is coming from the side of the corridor to which the exit sign is pointing to; 4) there is a fire in one part of the corridor (where there was smoke in the previous scene), making it impossible to use this path as the way out; 5) people running away from the side of the corridor to which the sign points, and towards the other exit (see Fig. 2 left). 


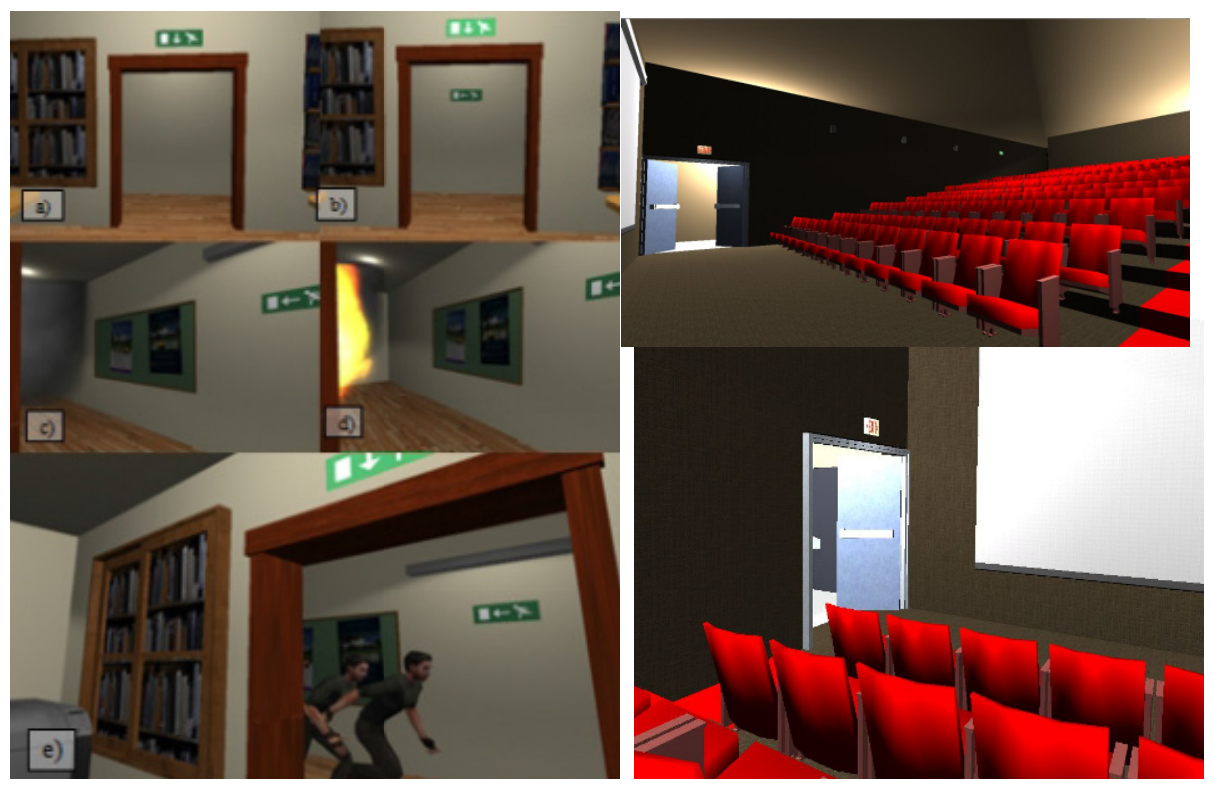

Fig. 2. Left) the five scenes of the exit-choice scene; right) two perspectives of the auditorium

Each scene evaluates different variables and goals. The variables that were identified and selected as essential to be assessed in the overall experiment are as follows: tendency to turn right or to turn left at corridor intersections (scene 1); tendency to follow signalling (scene 2); tendency to take risks in emergency situations (e.g. going through smoke or going the opposite direction - scene 3); Tendency to trust and follow people (scene 5). At each run, the player is told to evacuate as quickly as possible. The exit path selected, left or right, is saved.

\section{The Auditorium or Cinema Scenario}

The other role play consists of an auditorium with a certain inclination and entrance at two different levels: upper (near the rear of the auditorium) and lower, near the screen or stage (see Fig. 2 right).

The game starts with the avatar entering the auditorium using the top or rear entry and sitting at the top row. Meanwhile a siren alarm sounds and the player has to select one of four possibilities: a) fire alarm; b) theft alarm; c) emergency vehicle siren (ambulance); d) fire truck siren. Then, the player is told to select one exit: the top entry which was used to get in or the bottom one. The selected preference is saved and the experiment is repeated for the following combinations: i) using top entry and seating at top row; ii) using top entry and seating at bottom row; iii) access through bottom entry and seat at bottom row; iv) enter via same bottom entry and then seating at top row. The experiment goal is to figure out which is the exit preference for each of these possibilities: if there is a tendency to exit using the same way in, or using the nearest exit instead. 


\section{The Game Genre: First Person Shooter}

First Person Shooters (FPS) are characterised by placing players in a 3D-virtual world which is seen through the eyes of an avatar. When playing, user has the feeling of being actually on the location site, moving around, and giving the best possible sensation of immersion.

Although there are other possibilities, such as the use of CAVE for the recreation of Virtual Environments (VE) that provide a better feeling of immersion to the player, using SG is far more economic and feasible, without having to use expensive hardware and software, and yet such a technique offers a reasonable degree of resemblance.

The controls for the SG presented to the children follow the common standards for the FPS genre, using a combination of keyboard and mouse to move the character around the environment. The complete action mapping is as follows:

- Mouse movement - camera control, i.e. where the player is looking at;

- W - move forward;

- $\quad$ S - move backwards;

- $\mathbf{A}$ - move to the left;

- D - move to the right.

To improve usability and make it easier for kids with less gaming experience and such a keyboard-plus-mouse technique, a joystick was also used as an alternative.

\section{Data Collection and Result Analysis}

A group of 19 children from a local elementary school was selected to play the SG. Their main characteristics are presented in Table 1.

Table 1. Population sample's characteristics

\begin{tabular}{|l|c|}
\hline Data & Values \\
\hline Number of subjects & $19(100 \%)$ \\
\hline Male subjects & $9(47 \%)$ \\
\hline Female subjects & $10(53 \%)$ \\
\hline Minimum age & 6 \\
\hline Maximum age & 9 \\
\hline Mean age & 7,58 \\
\hline Age SD & 0,96 \\
\hline Left-handed & $4(21 \%)$ \\
\hline $1^{\text {st }}$ Grade & $2(11 \%)$ \\
\hline $2^{\text {nd }}$ Grade & $8(42 \%)$ \\
\hline $3^{\text {rd }}$ Grade & $3(16 \%)$ \\
\hline $4^{\text {th }}$ Grade & $5(26 \%)$ \\
\hline
\end{tabular}


All of them are used to interact with computers, tablets and video-games. In fact, almost all said having at least one game console at home (e.g. Playstation, PSP, Nintendo, Wii).

\section{Results from the Experiments}

Most prefer the keyboard-plus-mouse combination $(15-79 \%)$ instead the joystick (3 $-16 \%$ ). It was noted that the youngest children (aged 6 or 7 ) attending the $1^{\text {st }}$ or $2^{\text {nd }}$ grade, had more difficulties to understand the SG concept and to interact with it. The children of $3^{\text {rd }}$ and $4^{\text {th }}$ grades were more comfortable with the computer commands and the SG aim.

The exit-choice scenario was probably the more challenging of the two role plays and the one that kids enjoyed the most. Only two failed to see the emergency sign pointing left; they confessed that were not aware of its meaning though. These were the youngest (aged 7) so it is understandable their lack of knowledge.

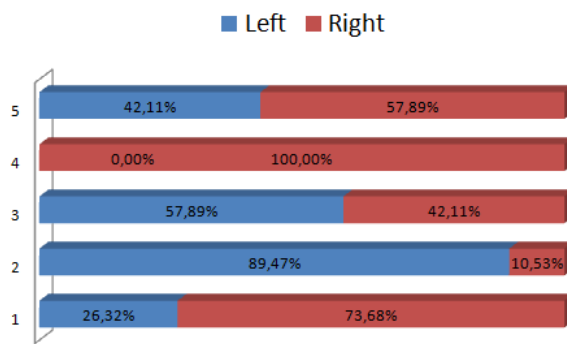

a)

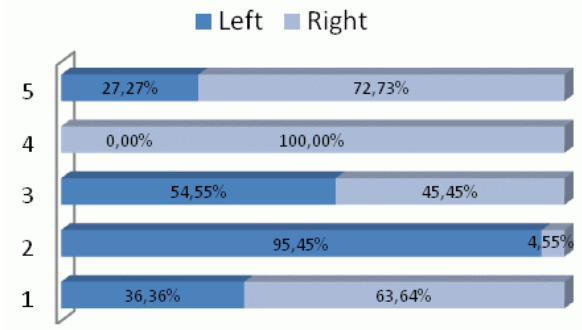

b)

Fig. 3. a) results in percentage for each exit-choice test scene; b) results of a similar test with a population of adults

Fig. 3a) shows the results in percentage of the exit-choice test scenario for the children. Fig. 3b) shows results from a similar test with a population sample of adults. Comparing both, it is clear the results are very similar. Only in scene 5, testing the tendency of following others, we realise that kids are more prone to follow the exit sign $(42.11 \%)$ than adults $(27.27 \%)$. Perhaps this fact is due to being children better educated to obey rules than adults. Analytical results are shown in Table 2.

Table 2. Results from the exit-choice scenario

\begin{tabular}{|l|r|r|}
\hline Scene & Left & Right \\
\hline 1. Tendency to turn left / right & 5 & 14 \\
\hline 2.Tendency to follow emergency signs & 17 & 2 \\
\hline 3.Tendency to go through smoke & 11 & 8 \\
\hline 4.Tendency to go through fire & 0 & 19 \\
\hline 5.Tendency to follow others & 8 & 11 \\
\hline
\end{tabular}


The Auditorium scenario was combined with the Alarm Id. There is a clear tendency to exit though the same entry. However, the last scene had the higher number of children using the top exit (nearer to the top row). When asked, the ones using this strategy said that perhaps it is better to use the nearest exit (although some did not use this strategy in the other scenes). It is clear that children learn fast. If the test was repeated, the results would clearly be quite different, proving that the SG is a valid means for teaching safety concepts.

Table 3. Results from the auditorium and alarm id scenarios

\begin{tabular}{|l|r|r|l|l|l|}
\hline $\begin{array}{l}\text { Auditorium } \\
\text { scenario }\end{array}$ & Top exit & Bottom exit & Alarm Id scenario & Right & Wrong \\
\hline $\begin{array}{l}1 \text { - Top entry / } \\
\text { Top row }\end{array}$ & $13(68 \%)$ & $6(32 \%)$ & 1 - Fire & $8(42 \%)$ & $11(58 \%)$ \\
\hline $\begin{array}{l}2 \text { - Top entry / } \\
\text { Bottom row }\end{array}$ & $5(26 \%)$ & $14(74 \%)$ & 2 - Theft alarm & $11(58 \%)$ & $8(42 \%)$ \\
\hline $\begin{array}{l}\text { 3- Bottom entry / } \\
\text { bottom row }\end{array}$ & $2(11 \%)$ & $17(89 \%)$ & $\begin{array}{l}3 \text { - Emergency } \\
\text { vehicle }\end{array}$ & $14(74 \%)$ & $5(26 \%)$ \\
\hline $\begin{array}{l}\text { 4 - Bottom entry } \\
\text { / Top row }\end{array}$ & $8(42 \%)$ & $11(58 \%)$ & 4 - Fire truck siren & $5(26 \%)$ & $14(74 \%)$ \\
\hline
\end{tabular}

The fire alarm id test showed that some of the children are acquainted with the various sirens and alarm sounds, although some are more confusing than others. A great majority clearly identified the sound of emergency vehicle (ambulance or police) with a very characteristic sound that they hear often. Odd to say is that only 5 (26\%) identified the fire truck siren. Most said that never heard or remember hearing such a sound. There was also some confusion with the fire and theft alarm sounds.

The youngest children (aged 6 and 7) were the ones that had more difficulties in this test; their environment knowledge is lower than the rest. Some of the kids from $4^{\text {th }}$ grade said to have some education on fire safety and escape strategies, from a teacher and a book concerning the study of the environment. Some said that a fire extinguisher should be available; when they were told there was none, one boy exclaimed: "that is wrong! There must be at least one fire extinguisher in such places!" These comments fortunately suggest that nowadays kids are fairly aware of the general importance of fire safety regulations.

\section{$5 \quad$ Conclusions and Future Work}

This paper presents the use of SG to acquire human behaviour when facing the urgent need of evacuating from an unknown building and having to deal with a set of unexpected events. This experiment was applied to a group of children aged between 6 and 9 years. The results are promising and extremely valuable for fire safety practitioners as well as for evacuation modellers, since data on human behaviour is scarce and much sought-after, particularly for specific groups such as children, elderly or people with disabilities. 
The knowledge elicited using this methodology might be used in evacuation simulators when trying to model situations with children, for instance. Their tendencies, as described in Table 2, were revealed and can be used to improve the behaviour of intelligent agents when trying to mimic children of these ages.

This method has proved to be useful for data collection as well as training. The children that participated in the experiments, at the end, were taught how they should behave in a real situation, and we are confident that the lessons learnt will be hardly forgotten. After the test, they showed a new confidence and knowledge on fire safety issues.

Future work is two-fold: i) continue to improve the scenarios and the data collection mechanisms, expanding the groups and possibly using massive data collection with the web version of the Unity3D SG; ii) apply machine learning algorithms to process the acquired data from human behaviour and use it to breed and grow artificial societies populating evacuation simulation models. The what-if scenarios and simulations that will be possible to execute using such tools are of paramount importance for emergency planning practitioners and fire safety engineers. The ultimate goal is to enhance the layout of buildings with respect to fire safety and to train their occupants in escape procedures thus helping saving lives and reducing injuries due to fires.

Acknowledgments. This project has been partially supported by FCT (Fundação para a Ciência e a Tecnologia), the Portuguese Agency for R\&D, under grant SFRH/BD/72946/2010. Authors wish to express their deep gratitude to the Centro Social Candal-Marco, Vila Nova de Gaia, Portugal, for allowing using their installations, and to the children that took part in this tests. We would also like to thank the invaluable comments from the anonymous reviewers that were much appreciated and taken into consideration.

\section{References}

1. Hays, R.: The effectiveness of instructional games: A literature review and discussion, Orlando, Florida, USA (2005)

2. Smith, S., Ericson, E.: Using immersive game-based virtual reality to teach fire-safety skills to children. Virtual Real. 13, 87-99 (2009)

3. Ericson, E.R.: Development of an immersive game-based virtual reality training program to teach fire safety skills to children (2007)

4. Balasubramanian, V., Massaguer, D., Mehrotra, S., Venkatasubramanian, N.: DrillSim: A Simulation Framework for Emergency Response Drills. In: Mehrotra, S., Zeng, D.D., Chen, H., Thuraisingham, B., Wang, F.-Y. (eds.) ISI 2006. LNCS, vol. 3975, pp. 237-248. Springer, Heidelberg (2006)

5. Gamberini, L., Cottone, P., Spagnolli, A., Varotto, D., Mantovani, G.: Responding to a fire emergency in a virtual environment: Different patterns of action for different situations. Ergonomics 46, 842-858 (2003)

6. Navarro, A., Pradilla, J.V., Rios, O.: Open Source 3D Game Engines for Serious Games Modeling. In: Alexandru, C. (ed.) Modeling and Simulation in Engineering, pp. 143-158 (2012) 
7. Ribeiro, J., Almeida, J.E., Rossetti, R.J.F., Coelho, A., Coelho, A.L.: Towards a serious games evacuation simulator. In: Troitzch, K.G., Möhring, M., Lotzmann, U. (eds.) 26th European Conference on Modelling and Simulation, ECMS 2012, Koblenz, Germany, pp. 697-702 (2012)

8. Almeida, J.E., Tiago, J., Neto, P., Faria, B.M., Rossetti, R.J.F., Coelho, A.L.: Serious Games for the Elicitation of Way-finding Behaviours in Emergency Situations. In: CISTI 2014 - 9a Conf. Ibérica de Sist. y Tecnol. de Información, Barcelona, Spain, pp. 2014-2019 (2014)

9. Almeida, J.E., Rossetti, R.J.F., Faria, B.M., Jacob, J.T., Coelho, A.L.: Towards a Methodology for Human Behaviour Elicitation: Preliminary Results. In: Affenzeller, Bruzzone, Jiménez, Longo, Merkuryev, Z. (eds.) The 26th European Modeling \& Simulation Symposium (EMSS 2014), Bordeaux, France, pp. 220-228 (2014)

10. Silva, J.F., Almeida, J.E., Rossetti, R.J.F., Coelho, A.L.: Gamifying evacuation drills. In: Iberian Conf. on Information Syst. and Tech., CISTI, Lisbon (2013)

11. Almeida, J.E., Rossetti, R.J.F., Aguiar, F., Oliveira, E.: Crowd Simulation Applied to Emergency and Evacuation Scenarios. In: Advances in Artificial Transportation Systems and Simulation, pp. 149-161 (2014)

12. Silva, J.F., Almeida, J.E., Rossetti, R.J.F., Coelho, A.L.: Gamifying Evacuation Drills. In: Third Iberian Workshop on Serious Games and Meaningful Play (SGaMePlay 2013), Lisbon, Portugal (2013)

13. Rossetti, R., Almeida, J.E., Kokkinogenis, Z., Gonçalves, J.: Playing Transportation Seriously: Applications of Serious Games to Artificial Transportation Systems. IEEE Intelligent Systems 28, 107-112 (2013)

14. Fernandes, R., Almeida, J., Rosseti, R.: A Collaborative Tourist System Using Serious Games. Adv. Inf. Syst. Technol. 206, 725-734 (2013)

15. Frey, A., Hartig, J., Zinkernagel, A., Moosbrugger, H.: The use of virtual environments based on a modification of the computer game Quake III Arena in psychological experimenting. Comput. Human Behav. 23, 2026-2039 (2007)

16. De Freitas, S.I.: Using games and simulations for supporting learning. Learn. Media Technol. 31, 343-358 (2006)

17. Kirriemuir, J., McFarlane, A.: Literature Review in Games and Learning. Future Lab Series, Report 8 (2004)

18. Almeida, J.E., Rossetti, R.J.F., Coelho, A.L.: Mapping 3D character location for tracking players' behaviour. In: Iberian Conference on Information Systems and Technologies, CISTI, Lisbon (2013)

19. Brown, B.B.: Delphi process: A methodology used for the elicitation of opinions of experts (1968)

20. Cordeiro, E., Coelho, A.L., Rossetti, R.J.F., Almeida, J.E.: Human Behavior Under Fire Situations - Portuguese Population. In: 2011 Fire and Evacuation Modeling Technical Conference, Baltimore, Maryland, August 15-16 (2011)

21. Hwang, V., Duchossois, G.P., Garcia-Espana, J.F., Durbin, D.R.: Impact of a community based fire prevention intervention on fire safety knowledge and behavior in elementary school children. Inj. Prev. 12, 344-346 (2006)

22. Jones, R.T., Kazdin, A.E., Haney, J.I.: Social validation and training of emergency fire safety skills for potential injury prevention and life saving. J. Appl. Behav. Anal. 14, 249-260 (1981)

23. Kokkinogenis, Z., Almeida, J.E., Rossetti, R.J.F.: NetLogo implementation for Crowd Evacuation. In: MECC 2013 - International Conference and Advanced School Planet Earth, Mathematics of Energy and Climate Change, Lisbon, Portugal (2013) 